J. Léger*, P. Czernichow

Pediatric Endocrinology Unit and Diabetes, Hôpital des Enfants-

167 Malades, Paris, France.

\section{DECREASED GROWTH VELOCITY DURING EARLY WEEKS OF LIFE IN INFANTS} WITH CONGENITAL HYPOTHYROIDISM.

Infants with congenital hypothyroidism (CH) have a normal size at birth.Growth during the first weeks of life has not yet been studied although $\mathrm{CH}$ offers a model to describe the effect of thyroid homone on growth during early infancy. Thyroid scan and thyroglobulin determination were performed in 47 infants with $\mathrm{CH}$ al lowing classification into the follawing groups: athyreosis $n=13$, ectopic $n=25$ and eutopic gland $n=9$. Infants were measured at birth, at diagnosis (less than 1 month of age) and 2, 4, 8 weeks after therapy. Height was expressed in standard dieviation score and corrected for gestational age according to intra and extrauterine growth standards of Largo et al. Bone age was retarded at birth and at diagnosis, epiphyseal surfaces of the knee were correlated with plasma T4 values. By contrast, height (mean $\pm \mathrm{SO}$ ) at birth was nomal $(0.3 \pm 0.8 \mathrm{SO})$ with identical distribution among the 3 subgroups. At diagnosis it was at $-0.1 \pm 0.6 \mathrm{SO}$, a value significantly different fram the value at birth $(p<0.05)$. After 2 weeks of therapy a continuous decline in grouth velocity was observed, reaching $-0.2 \pm 0.7 \mathrm{SO}$ at 6 weeks of life ( $p<0.02$ vs size at birth). Growth retardation was correlated with the intensity of thyroid deficiency. Mean height after 2 weeks of therapy was at $-0.6,-0.1,0.1$ SD in patients with respectively athyreosis, ectopic and eutopic gland. Catch-up grawth was observed thereafter, height reaching 0.3 SD at 12 weeks for the entire group.

In conclusion: A significant decreased height velocity was observed in $\mathrm{CH}$ before therapy and was more pronounced in severe hypothyroidism. In contrast to fetal period, thyroid hormone play an important role on growth during early weeks of life. This system is operating immediatly after birth.

Ch.Mengreli*, E. Sarafidou*, S. Tsagaraki*, S. Pantelakis* (Introd. by Ch. Theodoridis).

Institute of Child Health, Athens, Greece.

168 ALPHA-FETOPROTEIN ( $\alpha$-FP) MEASUREMENT IN ORIED BLOOD SPOTS:A DISCRIMINATING FACTOR BETWEEN TRANSIENT HYPERTHYROTROPINAEMIA AND CONGENITAL HYPOTHYROIDISM.

$\alpha-F P$ was measured in dried blood spots obtained between the 3rd and 7 th day of 1 ife by heel-prick from newborns within the operation of the Greek screening programme for congenital hypothyroidism (CH) in newborns, in order to check, if this analyte could serve as a second biochemical index in addition to thyrotropin (TSH) measurement for discriminating newborns with $\mathrm{CH}$ from those with transient hyperthyrotropinaemia $(\mathrm{TH}) \cdot \alpha-F P$ was measure by a RIA method. We studied 60 newborns with $\mathrm{CH}$ and 184 newborns with TH. The mean gestational age (GA) of $\mathrm{CH}$ group was $39,9 \pm 1,5$ weeks (mean $\pm S D$ ) and of $T H$ group $39,2 \pm 1,9$ weeks.Discriminant analysis was used after logarithmic transformation of $\alpha-f p$ values, in order to find the linear combination of $\alpha-F P a n d G A$, which best discriminates between $\mathrm{CH}$ and TH cases. The mean!SD of $\alpha-\mathrm{FP}$ in $\mathrm{CH}$ group was $32,6 \pm 31,1 \mu \mathrm{g} / \mathrm{ml}$, whereas the corresponding figure for $\mathrm{TH}$ group was $13,8 \pm 16,0 \mu \mathrm{g} / \mathrm{ml}$, difference statistically significant $(p<0,001)$. The discriminant function of $\log \alpha-F P$ and $G A$ was $35,57(\log \alpha-F P)+4,89(\mathrm{GA})-341,91$. This equation cTassifies a case to the $\mathrm{CH}$ group if it has a positive value and to the TH! group otherwise. The misclassification rate is about $26 \%$. In conclision $\alpha-F P$ values in dried blood spots are significantly higher in $\mathrm{CH}$ newborns than in $T H$ ones and the measurement of $\alpha-F P$ in $\mathrm{CH}$ screening programmes could offer a diagnostic aid in differentiating $\mathrm{CH}$ from TH newborns, especially those with border line TSti values.

169

C.R.Buchanan, R. Stanhope, J.Jones ${ }^{\star}$, P.Adlard ${ }^{\star}$, M. A. Preece Department of Growth and Development, Institute of Child Health, London, England.

GONADOTROPHIN, GROWTH HORMONE AND PROLACTIN SECRETORY DYSFUNCTION IN PRIMARY HYPOTHYROIDISM.

We have studied 5 prepubertal girls (age $6.7-12.3 \mathrm{yr}$ ) and 2 boys (age 13.3 and $14.2 \mathrm{yr}$ ) in early puberty (stage 2 genitalia) with primary hypothyroidism. Overnight serum hormone profiles (15-minute sampling) were performed at diagnosis and after 3 and 6 months of replacement therapy (Thyroxine $100 \mu \mathrm{g} / \mathrm{m}^{2} /$ day).

Pre-treatment, the girls had peak TSH levels $850-4800 \mathrm{mU} / \mathrm{h}$ with FSH concentrations raised (peak 3.9-19.5 U/1) above the LH levels (peak 1.8-3.7 U/1) which were non-pulsatile. Pelvic ultrasound showed small numbers of ovarian cysts without a multicystic morphology. Prolactin concentrations were elevated and pulsatile (peaks 800-4600 mU/l). Progressive falls in TSH, prolactin and FSH occurred during treatment. LH levels were unchanged in 3 girls but increased, becoming pulsatile in the 2 older girls, who also progressed to breast stage 2 by 3 months. GH pulse amplitude increased during treatment.

In contrast, the boys had less severe hypothyroidism. Pretreatment TSH levels were 210 and $1400 \mathrm{mU} / 1$; prolactin levels were elevated to 1200 and $1700 \mathrm{mU} / \mathrm{l}$. Gonadotrophin profiles showed pulsatile patterns appropriate for early puberty with LH predominating over FSH.

Raised FSH secretion occurs as a spectrum in children with primary hypothyrodism, even in those without abnormal sexual development.
F.Vermiglio*,M.Sidoti*,S.Battiato*,M.D.Finocchiaro*, M.Scaffidi*,D.Crupi*,F.De Luca, F.Trimarchi*.

170 Istituti di Clinica Medica e Clinica Pediatrica University of Messina, Italy.

ENDEMIC COGNITIVE AND NEUROMOTOR DEFICIT IN SCHOOLCHILDREN OF IODINE DEFICIENT AREAS.

Mental defects were found by Bender-Gestalt test,Santucci method, in $33 / 192(17.1 \%)$ euthyroid schoolchildren born between 1975 - 1980 in an endemic goiter and cretinism area in which goiter prevalence was $79 \%$ and daily iodine urinary excretion was $22.3+/-16.4 \mathrm{mcg}$.just in the years in which studied children were born. These defects are variously associated with goiter (36.4\%), short stature (15.1), bone age retardation (21.2\%) and with minor neuromotor disorders including hyporeflexia (21.2), hyperreflexia/clonus of the rotula and or foot $(30 \%)$, dyslalia $(6.1 \%)$. These findings could be considered as minor manifestations of neurological endemic cretinism. It must be noted that these defects are not only the clue of that severe endemia since the extension of the study iu another community of 119 schoolchildren living in an area with a goiter prevalence of $59 \%$ revealed a $12.6 \%$ children with comparable mental and neuromotor defects.Despite an actual sharp decrease in goiter prevalence in both areas (79-44\%, 59-26\%), these iodine deficiency disorders seem to persist hitherto. If neurological damage is due to iodine deficiency "per se" or to maternal hypothyroxinemia is still unclear.

\section{S Abusreweil*, L Tyfield*, D C L Savage}

\section{1}

Royal Hospital for Sick Children and Regional Screening Labotory, Southmead Hospital, Bristol, U.K.

SERUM THYROXINE (T4) AND THYROTROPHIN STIMULATINC HORMONE (TSH) LEVELS IN CHILDREN TREATEO FOR CONGENITAL HYPOTHYROIDISM

Between 1981 and 1985185,723 infants (93.7\% of newborn population) born in the South west of England were screened for congenital hypothyroidism using an immunoradiometric assay for TSH. 42 infants ( 16 boys and 26 girls) were diagnosed as having primary congenital hypothyraidism (inciderice $1: 4400$ ). Treatment and progress were monitored by local paediatricians.

Following therapy TSH remained elevated in $52 \%$ of infants at 3 montiss, $33 \%$ at 12 months, $24 \%$ between $2-3$ years and in one at 4 years.Serum $T 4$ was never below the normal range for age throughout the study period but was significantly higher in those children who had normal TSH levels.

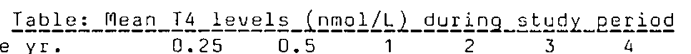

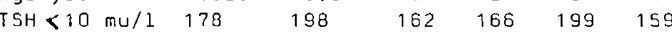

$\mathrm{TSH}>10 \mathrm{mu} / 1 \quad 120 \quad 131 \quad 113 \quad 93 \quad 152 \quad 128$

There was a wide range of L-thyroxine dosage at all age groups and it was those with the lower doses per $\mathrm{Kg}$ body weight who had the raised TSH levels. The clinical characteristics of the group were similar with satisfactory grouth and development in all children.

We conclude that a significant number of children treated for congenital hypothyroidism have raised TSH levels iri association with $T 4$ levels in the reported normal range during the first 4 years of life. Possible reasons for this will be discusser.

S. Hodges.* B. P. O'Malley.* P. G. F. Swift.* Introduced by D. C. L. Savage.

172 Department of Child Health \& Pharmacology + Therapeutics, University of Leicester. Department of Paediatrics. Leicester General Hospital. Leicester. UK OPTIMAL DAILY OOSAGE OF THYROXINE IN CHILDHDOD: A REAPPRAISAL.

In Brita in in 1990 the bio-availability of L.Thyroxine was increased by $11 \%$. Treatment of 13 hypothyroid children (7congenital, 6 juvenile. (3 - 16 years) was reassessed using a highly sensitive assay of T.S.H. T3, T4, Free T3 + Free T4.

At the beginning of the study 12 children had T.S.H. below the upper 1 imit of normal $(<5 \mathrm{MJ} /)$. At intervals of 4 weeks L Thyrox ine was reduced by 12.5 ug until the T.S.H. was elevated above nomal. The one child with an elevated T.S.H. had L. Thyroxine increased by $12.5 \mathrm{ug}$ at 4 weekly intervals unt is the T.S.H. fell into the nomal range $(0.3-5 \mathrm{~m} / \mathrm{L})$. The optimal dose was defined as the minimum dose to maintain T.S.H. $<5 \mathrm{MJ} /$,

Mean dose at start of study $108.5 \pm 4.7 \mathrm{ug} / \mathrm{M} / \mathrm{k} /$ day $/ 3.8 \pm .18 \mathrm{ug} / \mathrm{kg} /$ day. Mean opt imal dose was $92.5 \pm 4.0 \mathrm{ug} / \mathrm{M} F /$ day $/ 3.24 \pm 0.13 \mathrm{ug} / \mathrm{kg} /$ day. There was no difference in opt mal dosage in congenital or juvenile cases. Opt mal dose correlated strongly with both surface area $(r=0.98)$ and weight $(r=0.97)$. Some children had subtle behavioural signs of over-treatment initially; in none was bone age advanced. Mean values for T3, T4, Free T3 + Free T4 all fell at the upper limit of the normal range on both initial and opt inal dosage.

We conclude that current dosage recommendations for $L$. Thyroxine may be too high and highly sensitive T.S.H. assay assist in titration of dosage. 